\title{
Procedure frequency in the jaws related to implant location
}

\author{
Souheil Hussaini* \\ Department of Restorative Dentistry, Rutgers school of Dental Medicine, NJ, USA
}

\begin{abstract}
Introduction: The article demonstrates different procedures performed in different parts of the mouth that is of importance in the clinical practice of dental implants based on required procedures performed concurrently. An implant location is one of many factors that can influence a success or failure of dental implants.

Materials and method: This retrospective study has been derived based on an analysis of 200 random sample size of 1134 successfully treated patients with 4800 implants. Each procedure during implant treatment received a code as follows: 1: Surgery \& Restoration, 2: GBR, 3: GTR, 4: Block Bone graft, 5: Spreading, 6: Splitting, 7: Internal Sinus, 8: External Sinus, 9: PRF. Each of the 200 cases was examined in detail and the number of procedures added for every case and divided by the number of cases included in that category to get an average number of procedures more frequently performed in each zone. The zones are describe as five alveolar jaw regions, anterior mandible (Z1) with unique characteristics of anatomy, blood supply, pattern of bone resorption, posterior maxilla (Z2) with different form of bone quality and quantity, posterior mandible (Z3) with unique and high risk anatomical structures, anterior maxilla (Z4) with a need for soft and hard tissue grafting and other ancillary procedures, and posterior maxilla with sinus lift involvement $(Z 5)$ a location highly delicate due to communication with the respiratory mucosa and hence related to more ancillary procedures.
\end{abstract}

Results: The average number of procedures performed was Z5- 3.00, Z4- 1.92, Z3- 1.56, Z2- 1.78 and Z1- 1.

Discussion: The article discusses that implant location can lead number of ancillary procedures required to improved implant placement in different jaw zones. A thorough understanding of specifics of each zone clinically should help to improve preparation for treatment steps and prevent unexpected complications during treatment of dental implants.

Conclusion: There is a consistent trend of decreasing of the number of ancillary procedures that can be pre-estimated according to the location in different areas in the oral cavity. The estimated maximum is in the sinus area, followed by anterior maxilla, posterior mandible, maxillary premolars and anterior mandible.

\section{Introduction}

The causes of early implant failures during the osseointegration process include poor quality and quantity of bone and soft tissue [1-8], patient medical condition [2,6,8-10], unfavorable patient habits (bruxism, heavy long-term smoking, poor oral hygiene, others) $[3,4,6,8,11]$, inadequate surgical analysis and technique $[3,7-9,11]$ inadequate prosthetic analysis and technique $[3,7,8,11-13]$, suboptimal implant design and surface characteristics $[6,9,13]$, implant position or location [14] and unknown factors.

This article attempts to further investigate implant location as one of many factors in early stages of diagnosis that can predict the number of ancillary procedures in implant dentistry treatment.

Zones 1 to 5 is formulated to better analyze implant dentistry procedure preparation during diagnostic phase based on the location that has logical sequence during examination of the alveolar ridge of both maxilla and mandible to have preexisting information regarding the demands and the clinical requirements in different zones of the jaws. This article identifies all possible ancillary procedures in different alveolar jaw regions prior, during or after implant placement and accordingly facilitates dental implant placement with better understanding of what to expect.

Five zones are identified in this article in a logical sequence: Anterior mandible (Z1) with unique characteristics of anatomy, blood supply, pattern of bone resorption, posterior maxilla (Z2) with different form of bone quality and quantity, posterior mandible (Z3) with unique and high risk anatomical structures, anterior maxilla (Z4) with a need for soft and hard tissue grafting and other ancillary procedures, and posterior maxilla with sinus lift involvement (Z5) a location highly delicate due to communication with the respiratory mucosa. Z1-Z5 locations are related to the bone quality classification of Lekholm and Zarb [15].

\section{Materials and method}

From a data base of 1134 patients who had received 4800 dental implants from 2001 till August 17 $7^{\text {th }}$ 2015, randomly 200 files were selected and classified accordingly. A prosthodontist with no knowledge of the study criteria was requested to select 100 files from the data base in 2 separate sessions and present them for this study. The first 100 files (sample 1) had received Panoramic and Cone beam computed tomography (CBCT) (Appendix A) and the second 100 (sample 2)

Correspondence to: Hussaini S, BDS, MS, Director of Research, Oral Implantology Research Institute, \#39 Knowledge Village PO Box 502221, Dubai, UAE, Prosthodontist, Adjunct Instructor, Department of Restorative Dentistry, Rutgers school of Dental Medicine, NJ, USA, Tel: +971-50-4568100, +971-42956595; Fax: +971-4-2958757; E-mail: info@ID-SC.com

Key words: ancillary procedures, implant success, implant failure, jaw accessibility, healing time, implant location

Received: February 20, 2016; Accepted: March 24, 2016; Published: March 28 2016 
were collected from the patient received only panoramic radiograph during their diagnostic visit.

\section{Results}

\section{Number of procedures}

Each procedure during implant treatment received a code as follows: 1: Surgery \& Restoration, 2: GBR, 3: GTR, 4: Block Bone graft, 5: Spreading, 6: Splitting, 7: Internal Sinus, 8: External Sinus, 9: PRF. Each of the 200 cases was examined in detail and the number of procedures added for every case and divided by the number of cases included in that category to get an average number of procedures per class.

The data in Table 1, relates to the number of procedures in each class, demonstrated that out of 200 samples Class V- required an average of 3.00 procedures for each implant with all ancillary procedures that was required to complete the treatment, followed by Class IV that required an average of 1.92 procedures, class III- an average of 1.56 procedures, class II- an average of 1.78 procedures and class I- 1 procedure, respectively.

\section{Statistical analysis}

An inferential and qualitative Statistical analysis was done by computing and using Sample means, Sample Standard Deviation. Students' T Test is used to compare means and proportions, inference given on the basis of value of $\mathrm{P}$ (Statistical significance difference was denoted when $\mathrm{P}<0.05)$.

The Mann-Whitney test is used to compare differences between independent classifications under minimum, maximum and average of HFU and time.

One Way ANOVA is used to find significant difference between CBCT and PAN.

\section{Statistical observations}

Test Statistic -2.6933 (ratio between the difference to the standard error)

$P$ Value $<0.05 \quad(\mathrm{p}=0.00714)$

The $t$-statistic is a ratio of the departure of an estimated parameter from its notional value and its standard error (Figure 1).

\section{Null hypothesis}

Different areas in the oral cavity have no effect on number of procedures during an implant placement procedure.

\section{Alternative hypothesis}

Different areas in the oral cavity have an effect on number of procedures during an implant placement procedure.

\section{Individual verifications}

- Mann Whitney Test showed evidence of Statistical Significant Difference between Classifications 1 and $2(\mathrm{P}<0.001)$

- Mann Whitney Test showed evidence of Statistical Significant Difference between Classifications 1 and $3(\mathrm{P}<0.001)$

- Mann Whitney Test showed marginal evidence of Statistical Significant Difference between Classifications 1 and 4 $(\mathrm{P}=0.0495)$

- Mann Whitney Test showed evidence of Statistical Significant Difference between Classifications 1 and $5(\mathrm{P}<0.001)$

- Mann Whitney Test showed evidence of Statistical Significant Difference between Classifications 2 and $3(\mathrm{P}<0.001)$

- Mann Whitney Test showed marginal evidence of Statistical Significant Difference between Classifications 2 and 4 $(\mathrm{P}=0.05215)$

- Mann Whitney Test showed evidence of Statistical Significant Difference between Classifications 2 and $5(\mathrm{P}<0.001)$

- Mann Whitney Test showed evidence of Statistical Significant Difference between Classifications 3 and $4(\mathrm{P}<0.001)$

- Mann Whitney Test showed evidence of Statistical Significant Difference between Classifications 3 and $5(\mathrm{P}<0.001)$

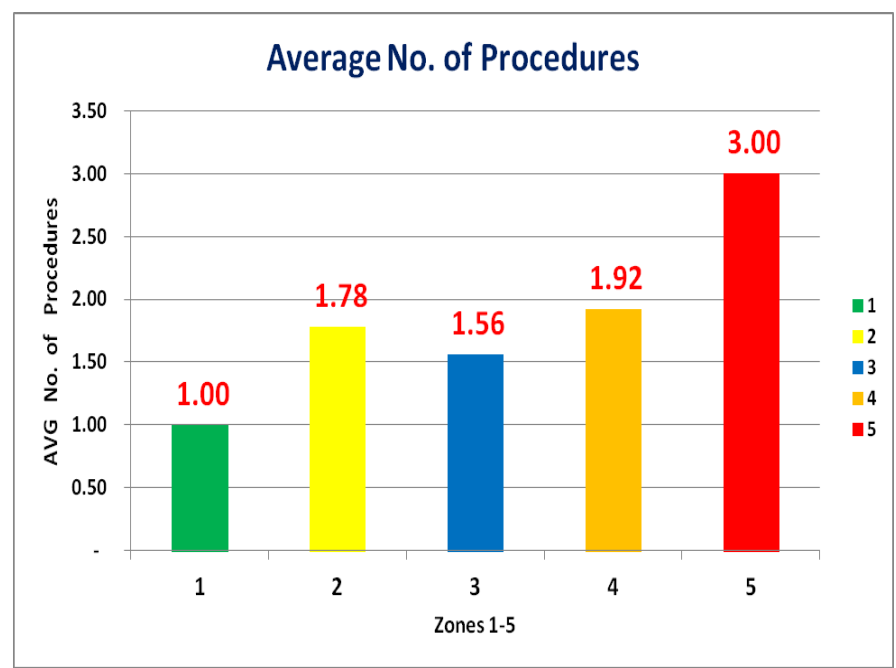

Figure 1. Graphical represenatation of average number of procedures per Level (Sample 1 and 2) required to complete the surgical procedure per classification in different areas in the mouth.

Table 1. Average No. of procedures per Level (Sample 1 and 2) required to complete the surgical procedure per classification in different areas in the mouth.

\begin{tabular}{|c|c|c|c|c|c|c|c|}
\hline $\begin{array}{l}\text { Zone } \\
(1-5)\end{array}$ & $\begin{array}{c}\text { Sum of No. of } \\
\text { Procedures (Sample 1) }\end{array}$ & $\begin{array}{l}\text { No. of Cases } \\
\text { (Sample 1) }\end{array}$ & $\begin{array}{c}\text { Average No. of } \\
\text { Procedures per Level } \\
\text { (Sample 1) }\end{array}$ & $\begin{array}{l}\text { Sum of No. of } \\
\text { Procedures } \\
\text { (Sample 2) }\end{array}$ & $\begin{array}{l}\text { No. of Cases } \\
\text { (Sample 2) }\end{array}$ & \begin{tabular}{|c|} 
Average No. of \\
Procedures per Level \\
(Sample 2)
\end{tabular} & $\begin{array}{c}\text { Average No. of } \\
\text { Procedures per Level } \\
\text { (Sample 1\&2) }\end{array}$ \\
\hline 1 & 14 & 14 & 1.00 & 4 & 4 & 1.00 & 1.00 \\
\hline 2 & 37 & 19 & 1.95 & 47 & 29 & 1.62 & 1.78 \\
\hline 3 & 53 & 33 & 1.61 & 47 & 31 & 1.52 & 1.56 \\
\hline 4 & 65 & 31 & 2.10 & 49 & 28 & 1.75 & 1.92 \\
\hline 5 & 9 & 3 & 3.00 & 24 & 8 & 3.00 & 3.00 \\
\hline Total & 178 & 100 & & 171 & 100 & & \\
\hline
\end{tabular}


- Mann Whitney Test showed evidence of Statistical Significant Difference between Classifications 4 and $5(\mathrm{P}<0.001)$

Overall, there is a significant difference between each classification $(\mathrm{P}<\mathbf{0 . 0 0 1})$

$\begin{array}{lll}\text { Procedures } & 1^{\text {st }} & 2^{\text {nd }} \\ \text { Average } & 1.780 & 1.710 \\ \text { STD } & 0.848 & 0.743\end{array}$

Test Statistic 0.62 (ratio between the difference to the standard error)

P Value $\quad 0.54 \quad 0.57$

There is no significant difference between number of Procedures performed with CBCT and with PAN.

\section{Discussion}

There are few literature reports that attempt to study implant location, among a multitude of other factors, to determine its influence on the success or failure of dental implant treatment. Becker et al. [16] in a prospective study evaluated 282 implants placed in the maxillary and mandibular molar positions. The 6-year cumulative success rate (CSR) for maxillary posterior implants was $82.9 \%$, for mandibular posterior, $91.5 \%$. He concluded that CSR in the posterior regions is lower than usually reported for anterior regions of the maxilla and mandible due to differences in bone quality and quantity. Eckert et al. [17] in a retrospective study assessed 1170 endosseous implants placed in partially edentulous jaws: anterior maxilla, posterior maxilla, anterior mandible, and posterior mandible. In his report, location of implants did not appear to have any effect on implant survival, implant fracture rates, screw loosening, or screw fracture. Parein et al. [18] in a longterm retrospective study analyzed 392 consecutively placed Branemark implants that were inserted in 152 partially edentulous posterior mandibles and restored with 56 crown and 168 bridge restorations. The CSR of all implants in the posterior mandible was $89.0 \%$ at 6 years. Fewer complications were found in implant prostheses located exclusively in the premolar region versus molar and mixed molarpremolar implant restorations. Drago [14] investigated the locationrelated osseointegration of 673 implants placed in 169 patients that were observed from 7 months to 8 years following occlusal loading. An implant osseointegration was $89.1 \%$ in the anterior maxilla, $71.4 \%$ in the posterior maxilla, $96.7 \%$ in the anterior mandible, and $98.7 \%$ in the posterior mandible. Moy et al., [19] analyed implant failure rates and associated risk factors, observed implant failure of $8.16 \%$ in the maxilla and $4.93 \%$ in the mandible. Increased age (over 60) was strongly associated with the risk of implant failure. Bass et al. [20] evaluating 303 patients with 1097 implants over 3-year period assessed the success rate of implants in the maxilla at $93.4 \%$ and $97.2 \%$ in the mandible. Poor bone quality played the major role in implant failure rate with bone quantity demonstrating less importance. All presented reports appear to agree that the CSR of dental implants is generally high and that implant location plays an important role in implant success. CSR of implants in the mandible seems to be slightly higher than in maxilla-about a $4 \%$ difference. The success rate of implants in the anterior regions seems to be higher than in the posterior regions of the jaws, mostly due to the quality of bone: about $12 \%$ difference between anterior maxilla and posterior maxilla, and about $4 \%$ difference between anterior mandible and posterior mandible. On the basis of reviewed literature reports, an implant treatment in the anterior mandible appears to be the most successful. The posterior maxilla appears to be the least successful region of the jaws for implant rehabilitation.

\section{Conclusion}

There is a consistent trend of decreasing of the number of ancillary procedures that can be pre-estimated according to the location in different areas in the oral cavity. The estimated maximum is in the sinus area, followed by anterior maxilla, posterior mandible, maxillary premolars and anterior mandible.

\section{References}

1. Tolstunov L (2006) Dental implant success-failure analysis: a concept of implant vulnerability. Implant Dent 15: 341-346. [Crossref]

2. Albrektsson T, Lekholm U (1989) Osseointegration: current state of the art. Dent Clin North Am 33: 537-554. [Crossref]

3. Tolstunov Len (2007) Implant zones of the jaws: implant location and related success rate. J Oral Implantol 33: 211-220. [Crossref]

4. Lemmerman KJ, Lemmerman NE (2005) Osseointegrated dental implants in private practice: a long-term case series study. J Periodontol 76: 310-319. [Crossref]

5. Iezzi G, Degidi M, Scarano A, Perrotti V, Piattelli A (2005) Bone response to submerged, unloaded implants inserted in poor bone sites: a histological and histomorphometrical study of 8 titanium implants retrieved from man. J Oral Implantol 31:225-233. [Crossref]

6. Rosenberg ES, Cho SC, Elian N, Jalbout ZN, Froum S, et al. (2004) A comparison of characteristics of implant failure and survival in periodontally compromised and periodontally healthy patients: a clinical report. Int J Oral Maxillofac Implants 19: 873-879. [Crossref]

7. Degidi M, Piattelli A (2005) 7-year follow-up of 93 immediately loaded titanium dental implants. J Oral Implantol 31: 25-31. [Crossref]

8. Kourtis SG, Sotiriadou S, Voliotis S, Challas A (2004) Private practice results of dental implants. Part I: survival and evaluation of risk factors; Part II: surgical and prosthetic complications. Implant Dent 13: 373-385. [Crossref]

9. El Askary AS, Meffert RM, Griffin T (1999) Why do dental implants fail? Part I. Implant Dent 8: 173-185. [Crossref]

10. Ruggiero SL, Mehrotka B, Rosenberg TJ, Engroff SL (2004) Osteonecrosis of the jaws associated with the use of bisphosphonates: a review of 63 cases. J Oral Maxillofac Surg 62: 527-534. [Crossref]

11. Ashley ET, Covington LL, Bishop BG, Breault LG (2003) Ailing and failing endosseous dental implants: a literature review. J Contemp Dent Pract 4: 35-50. [Crossref]

12. Kitamura E, Stegaroiu R, Nomura S, Miyakawa O (2004) Biomechanical aspects of marginal bone resorption around osseointegrated implants: considerations based on a three-dimensional finite element analysis. Clin Oral Implants Res 15: 401-412. [Crossref]

13. Steigenda JT, Al-Shammari KF, Nociti FH, Misch CE, Wang HL (2003) Dental implant design and its relationship to long-term implant success. Implant Dent 12 : 306-317. [Crossref]

14. Drago CJ (1992) Rates of osseointegration of dental implants with regard to anatomic location. J Prosthodont 1: 29-31. [Crossref]

15. Lekholm, U, Zarb GA (1985) Patient selection and preparation. In: Branemark, PI, Zarb GA, Albrektsson T (edn) Tissue integrated prosthesis: Osseointegration in clinical dentistry. Quintessence Publishing Co, Chicago, USA: 199-208. [Crossref]

16. Becker W, Becker BE, Alsuwyed A, Al-Mubarak S (1999) Long-term evaluation of 282 implants in maxillary and mandibular molar positions: a prospective study. $J$ Periodontol 70: 896-901. [Crossref]

17. Eckert SE, Wollan PC (1998) Retrospective review of 1170 endosseous implants placed in partially edentulous jaws. J Prosthet Dent 79: 415-421. [Crossref]

18. Parein AM, Eckert SE, Wollan PC, Keller EE (1997) Implant reconstruction in the posterior mandible: a long-term retrospective study. J Prosthet Dent 78: 34-42. [Crossref] 
19. Moy PK, Medina D, Shetty V, Aghaloo TL (2005) Dental implant failure rates and associated risk factors. Int J Oral Maxillofac Implants 20: 569-577. [Crossref]
20. Bass SL, Triplett RG (1991) The effect of preoperative resorption and jaw anatomy on implant success: a report of 303 cases. Clin Oral Implants Res 2: 193-198. [Crossref]

Copyright: $\odot 2016$ Hussaini S. This is an open-access article distributed under the terms of the Creative Commons Attribution License, which permits unrestricted use, distribution, and reproduction in any medium, provided the original author and source are credited. 